\title{
LETRAMENTOS CRÍTICOS E FORMAÇÃO DE PROFESSORES DE INGLÊS: CURRÍCULOS E PERSPECTIVAS EM EXPANSÃO
}

\author{
Critical Literacies and English Teacher Education: Expanding Curricula and Perspectives
}

\author{
Ana Paula DUBOC - FMU / USP PG (Capes) \\ Daniel Mello FERRAZ - FATEC / UMC / USP PG
}

RESUMO: Os atuais processos globais, em consonância com o desenvolvimento de novas tecnologias das últimas décadas, posicionam as questões de língua como das mais relevantes, em função da alta conectividade e interação entre os sujeitos. $\mathrm{O}$ inglês particularmente assume novos papéis para além de sua função comunicativa, sendo agora repensado como ferramenta crítica e participativa. Diante do novo cenário, como podemos redesenhar nossos contextos de formação docente, seja a formação inicial ou a continuada, de maneira que a formação do professor de inglês possa melhor responder às atuais demandas? Este artigo toma os novos letramentos como aporte teórico e prioriza o trabalho dos letramentos críticos e a noção de expansão de perspectivas. Os autores discutem duas atividades implementadas em cursos de formação continuada que tiveram como objetivos discutir a formação docente e a práxis dos professores participantes no intuito de transpor para a sala de aula de inglês esses debates globais recentes.

PALAVRAS-CHAVE: língua inglesa; formação de professores, novos letramentos; letramento crítico, expansão de perspectivas

\begin{abstract}
The current global processes connected with the development of new technologies in recent decades have positioned language within a relevant debate - due to the high connectivity and interaction among individuals. English in particular takes on new roles - beyond its communicative function - and is being reshaped as a critical and participatory tool. Within this new scenario, how can we redesign our contexts of teacher education, whether initial or continuing education, so that the formation of the English teacher can better meet the current demands? This article takes new literacies as the theoretical framework and prioritizes critical literacies and the notion of expanding perspectives. The authors discuss two activities implemented in continuing education courses which focused on teacher education and teachers' praxis in order to transpose these recent global discussions into the English classroom.
\end{abstract}

KEY WORDS: English language, teacher education, new literacies, critical literacies, expanding perspectives

\section{INTRODUÇÃO}

Never before have the technological, economic and social changes around us occurred so rapidly or been so destabilizing.

Pierre Levy (2001), Becoming Virtual: Reality in the Digital Age

As sociedades contemporâneas vêm sofrendo expressivas mudanças, revoluções, reconceitualizações e transformações advindas das epistemologias digitais, cujas implicações 
necessitam problematização e expansão do conhecimento nos diversos campos de pesquisa. Castells (2000) defende que "a tecnologia é a sociedade" sinalizando que "a sociedade [atual] não pode ser entendida ou representada sem seus instrumentos tecnológicos" (ibidem, p.5), o que implica que através das tecnologias da informação e comunicação, estamos globalmente conectados de alguma forma. Levy (2001) contribui para o debate e alerta para um paradoxo: ao mesmo tempo que essa "considerada" conectividade global através das novas tecnologias pode gerar um fluxo caótico de informações e confusão intelectual, estamos vivendo uma era sem precedentes em relação às possibilidades positivas que elas podem oferecer.

Diante deste cenário marcado por processos globais cada vez mais múltiplos e heterogêneos, o ensino e a aprendizagem de línguas estrangeiras experimentam grande revalorização em virtude da interconectividade e da interdependência entre essas sociedades globalizadas. Conforme discutem teóricos como Edwards e Usher (2008) e Rizvi e Lingard (2010), a compressão do espaço e do tempo nos atuais processos de globalização produz e é produzida por novas formas de comunicação entre os sujeitos, uma discussão que coloca questões de língua como uma das mais relevantes.

No entanto, mais do que adotarmos uma abordagem constatatória no que diz respeito ao aumento exponencial da interação e produção de sentidos entre esses sujeitos da era digital por meio das mais diversas linguagens, este artigo prioriza a revolução ontológica trazida pela cibercultura (cf. Wark, 2006), marcada por re-conceitualizações relevantes ao nosso campo de atuação. Nos termos de Knobel e Lankshear (2007), as sociedades globalizadas experimentam não apenas o surgimento de novos aparatos digitais - o "new technical stuff'- mas sobretudo expressivas revisões conceituais - ou "new ethos stuff" (ibidem: 07). Em outras palavras, de uma sociedade tipográfica, passamos agora a um cenário pós-tipográfico cujo processo de significação ganha um caráter multimodal sem precedentes (cf. Cope e Kalantzis, 2000), fundamentado agora por um novo conceito de sujeito, de conhecimento e de língua.

Assim, o inglês não apenas passa a ser usado por mais pessoas localizadas nos mais diversos espaços (físicos e virtuais), mas também passa a assumir novos papéis: de língua franca com fins estritamente comunicativos, a língua inglesa vem sendo entendida por teóricos comprometidos com questões linguísticas como ferramenta crítica e participativa (cf. Guilherme, 2007; Pennycook, 1994; Warschauer, 2000). Pennycook (1994), por exemplo, privilegia um conceito de língua de forma a destacar a presença de ideologias, valores e normas na história e nos usos do inglês. Nessa mesma linha, Warschauer (2000) vê a questão da agência como elemento-chave no papel do inglês global, em que passaria a ser usado para a expressão da identidade e da voz. 


\title{
DOSSIÊ ESPECIAL \\ JORDÃO (org.) Letramentos e Multiletramentos no Ensino de Línguas e Literaturas.
}

Revista X, vol.1, 2011

Justamente por nos colocarmos em favor desses debates contemporâneos que advogam um ensino de inglês voltado para a criticidade e o agenciamento do sujeito digital, este artigo afirma a necessidade de repensar a formação docente, seja ela inicial ou continuada, sob a perspectiva dos letramentos críticos (cf. Muspratt et al, 1997; Shor, 2009; Street, 1995, 1998, 2003) como condição para o que Monte Mór tem chamado de “expansão de perspectivas" (2009, 2010, 2011) nas salas de aula de línguas estrangeiras.

Assim, as atividades que compartilhamos a seguir ilustram algumas ações em contextos de formação docente à luz deste aporte teórico. Ao trazermos nossas experiências pessoais, não intentamos oferecer modelos de prática pedagógica do ensino de inglês, mas discutir atividades advindas de nossas apropriações teóricas, corroborando, assim, aquilo que Lankshear e Knobel (2003) denominam de "performance epistemology", ou seja, uma epistemologia de desempenho na ausência de modelos pré-estabelecidos da era digital.

\section{NOVOS LETRAMENTOS: ALGUMAS REVISÕES CONCEITUAIS}

\author{
From a sociocultural perspective literacy is a matter of social practices. Literacies are \\ bound up with social, institutional and cultural relationships, and can only be understood \\ when they are situated within their social, cultural and historical contexts. \\ Lankshear \& Knobel (2003), “From Reading to the New Literacy Studies”
}

Conforme situa Street (1995, 1998, 2003), o conceito de novos letramentos data do final da década de oitenta e do início dos anos noventa em resposta à necessidade de expandir a noção liberal de letramento, ou o modelo autônomo de letramento como o próprio autor (1995) define, caracterizado como um conjunto monolítico de habilidades de leitura e de escrita e adquirido de forma isolada do contexto ideológico e cultural do qual os sujeitos fazem parte. Letramento na acepção convencional é, portanto, entendido como a habilidade de ler e de escrever um código linguístico, enquanto que os novos letramentos constituem uma expansão daquela acepção de forma a considerar os aspectos sócio-ideológicos inerentes às práticas de leitura.

Essa revisão conceitual de letramento foi impulsionada por três principais fatores (cf. Lankshear e Knobel, 2003), a saber: a pedagogia crítica de Paulo Freire, a necessidade de reforma curricular nos Estados Unidos nos anos sessenta e a emergência dos estudos socioculturais. Assim é que teóricos começam a discutir que a aprendizagem da língua não se reduz ao domínio de um código ou técnica de escrita, pois esta encontra-se situada politica e ideologicamente nos diferentes espaços sociais e culturais (cf. Soares, 2005). 
Publicações mais recentes, como as de Lankshear e Knobel (2003, 2007), Gee (2004), Kress (2000, 2003) e Cope e Kalantzis (2000), têm rediscutido essa acepção de novos letramentos articulando-as mais detidamente com as novas maneiras de pensar e aprender num contexto pósindustrial tecnológico/digital. Mills (2010), por exemplo, explica que os teóricos têm enfatizado os potenciais inovadores e produtivos das práticas de letramento em ambientes eletrônicos. Ainda segundo as palavras da autora, "there is recognition that interpreting and representing ideas and information in social contexts, both inside and outside of schools, is increasingly digitalized" (Mills, 2010: 248).

Assim, as novas maneiras de pensar e aprender emergentes na era digital perpassam as dimensões operacionais, culturais e críticas (Lankshear e Snyder, 2010). Nas palavras dos autores (ibidem), os educadores que advogam em favor dos novos letramentos optaram por privilegiar o aspecto social à frente dessas dimensões, enfatizando, assim, seu caráter sociocultural, uma vez que essa foi pormenorizada pelas pedagogias convencionais. Segundo Lankshear e Knobel (2003: 9): "[W]e have defined literacies as socially recognized ways of generating, communicating and negotiating meaningful content through the medium of encoded texts within contexts of participation in Discourses".

Ao priorizar o aspecto sócio-cultural no lidar com os diversos modos representacionais, os novos letramentos são acompanhados de uma orientação crítica, pautada prioritariamente por um trabalho de letramento crítico, qualquer que seja a natureza desses modos (verbais ou não verbais, orais ou escritos, impressos ou digitais).

O conceito de letramento crítico advém de contribuições da teoria crítica de educação, com influência da pedagogia de Paulo Freire (Muspratt et al, 1997). No entanto, o letramento crítico atualmente discutido difere da pedagogia freireana na medida em que se pauta numa acepção de crítica muito mais voltada para a problematização de questões sociais, em detrimento de um projeto emancipatório (cf. Pennycook, 2001). Assim é que letramento crítico configura-se não como método pré-estabelecido, mas como postura diante de um texto com vistas à compreensão dos privilégios e apagamentos nas práticas sociais (cf. Comber, 2001). Tal orientação, portanto, desafia o status quo educacional refraseando e ressignificando o conceito "original" de alfabetização e toda a homogeneidade e fixidez que este conceito encerra no que se refere ao processo de significação.

Em âmbito nacional e voltando-se para contextos de ensino de línguas estrangeiras, publicações como as de Monte Mór $(2009$, 2010, 2011) vêm sinalizando a relevância do trabalho de letramento crítico como prática de leitura comprometida com a expansão de perspectivas do aluno. Tal expansão consiste no exercício de construção de sentidos nas dimensões individual, comunitária 
e global, de forma a relacioná-las e, sobretudo, compreendê-las em suas semelhanças e diferenças. Nos termos de Menezes de Souza (2011), trata-se do desenvolvimento da percepção do aluno quanto à constituição coletiva de sua linguagem e da natureza heterogênea e situada da realidade.

Diante das contribuições teóricas acima discutidas, este artigo propõe discutir duas atividades desenvolvidas em cursos de Pós-Graduação Lato Sensu voltados para professores de língua inglesa. Os cursos são oferecidos anualmente em duas instituições de Ensino Superior do setor privado, localizadas no Estado de São Paulo. Conforme verá o leitor, enquanto a primeira atividade volta-se para os conceitos de leitura, interpretação e visões de mundo por meio do trabalho de letramento visual, a segunda revisita os conceitos de comunicação e falante ideal nos atuais processos de globalização por meio da adoção de uma abordagem crítica no lidar com habilidades orais. Ambas sinalizam um denominador-comum: o tratamento de conceitos com vistas à ampliação de perspectivas por meio do trabalho de letramento crítico, justamente o fio condutor deste artigo.

\section{LEITURA, INTERPRETAÇÃO E LETRAMENTO VISUAL}

Nesse primeiro exemplo, descrevemos o redesenho curricular de um curso de formação continuada à luz dos novos letramentos para, em seguida, discutirmos de que forma as atividades bem como as discussões realizadas pelos alunos-professores compuseram, segundo nossa interpretação, práticas dentro dos movimentos dos novos letramentos, com ênfase para uma atividade que focaliza o letramento visual.

A aula contou com aproximadamente quinze alunos-professores ou coordenadores de inglês de escolas públicas ou privadas da região de Mogi das Cruzes, no Estado de São Paulo. Como se tratava de um curso de pós-graduação cuja premissa é a discussão acadêmica, na primeira parte da aula focalizamos a discussão do livro intitulado Oficina de Leitura (Kleiman, 1992) e a sua relação com as visões de leitura proposta por nós educadores, seguida de discussão do artigo EELT Education through English Language Teaching (Ferraz, 2010). O intuito dessa primeira parte consistia em discutir as duas visões de leitura sugeridas por Kleiman, quais sejam, a leitura crítica (Critical Reading) e o letramento crítico (Critical Literacy). A discussão que seguiu baseou-se no outro artigo referido, o qual se volta para duas percepções sobre o ensino de língua inglesa no Brasil: "a conventional one - built upon the fields of linguistics and applied linguistics and a socioculturaloriented one - built on the cultural studies field and on the new literacies practices" (Ferraz 2010: 01). Feitas essas discussões, discutimos a possibilidade de leitura de imagens (fotografias, cenas de 
filmes, imagens televisivas, imagens digitais etc) sob as perspectivas dos novos letramentos, com ênfase para o trabalho de letramento crítico no lidar com diferentes modos textuais.

Assim, os alunos foram convidados a trabalhar a leitura de imagens, bem como expansão do conceito de interpretação de imagens fotográficas. Os procedimentos pedagógicos são os que se seguem, os quais poderiam ser adaptados pelos alunos-professores em seus contextos escolares. $\mathrm{Na}$ primeira etapa, o professor discute com os alunos a possibilidade da leitura de imagens fotográficas. Complementa com o fato de que, muitas vezes, nosso olhar é "treinado" ou "forçado a ver de "certas maneiras", ou seja, somos treinados a ver da maneira que "todas as pessoas" ou o status quo vêem, prática essa denominada habitus interpretativo (Monte Mór, 1999). No contexto do letramento crítico, essa reprodução de "olhares" forma, geralmente, um tipo de cidadão: aquele que reproduz uma interpretação dada (ibidem). Uma segunda etapa consiste em mostrar as imagens através de slides (Anexo 1 - figura 1). Para cada imagem projetada, os alunos são convidados a lê-la (interpretá-la) com base nas questões previamente discutidas (a questão do "olhar treinado" e a expansão interpretativa). Em outras palavras, o professor instiga os alunos a produzirem uma interpretação daquela imagem que seja diferente de interpretações já concebidas ou legitimadas pelo "olhar treinado".

Além da preocupação com o objetivo linguístico - os alunos realizaram suas interpretações em inglês - essa atividade focalizou algumas questões centrais discutidas pelos novos letramentos, tais como elucidações de natureza social e ideológica, a possibilidade de interpretações e de diferentes visões do mundo, a possibilidade de leitura de imagens, questões de poder (no caso, "Quem possui o poder de decisão do que constitui uma interpretação "válida" de uma determinada imagem? O professor? Os alunos? Ambos?”) e ainda a discussão sobre o conceito de verdade (“Quais verdades/ interpretações são validadas, aceitas, negociadas?").

Os registros da atividade desenvolvida evidenciam a emergência de interpretações bastante divergentes, apontando para o fato de que, quando "desafiados" a produzir diferentes interpretações, os alunos-professores iniciam um processo de desconstrução do olhar treinado ao perceberem as várias possibilidades de interpretações para uma única imagem.

\section{COMUNICAÇÃO E FALANTE IDEAL EM TEMPOS GLOBAIS}

Conforme brevemente exposto na introdução deste artigo, teóricos voltados para as implicações dos atuais processos globais vêm repensando o papel de inglês para além de ferramenta 
comunicativa, revisitando, com isso, conceitos subjacentes como "comunicação" e "falante ideal", agora entendidos sob a lógica da heterogeneidade e da diferença

Ao discutir questões de cosmopolitanismo, globalização e inglês global, Ives (2009), por exemplo, atenta para a não-neutralidade no processo comunicativo, argumentando que a comunicação é legitimada por aquele que detém 'maior' ou 'melhor' inteligibilidade linguística. Pennycook (1994) e Warschauer (2000), por sua vez, contribuem para o debate na medida em que promovem a crítica ao conceito de inglês como língua franca ou língua internacional por serem conceitos que parecem tangenciar questões de ideologia e poder presentes nos diversos usos do inglês contemporâneo.

A questão do falante ideal é bastante discutida por Graddol (1997), cujos apontamentos preveem um tratamento mais fluido a conceitos que outrora costumavam ser bem delimitados, como a idéia de nação e de identidade nacional. A mesma ponderação é trazida por Yano (2009) quando este trata do reconhecimento de novas variações do inglês produzidas em contextos transnacionais. $\mathrm{O}$ autor ainda ressalta que em tais contextos, preserva-se agora tanto uma inteligibilidade internacional quanto a identidade daquele determinado contexto, cujo falante estrangeiro não é mais obrigado a tomar o falante nativo como modelo-padrão.

Essas e outras questões foram discutidas com os alunos-professores de nosso segundo contexto de formação docente, em uma instituição localizada na cidade de São Paulo, durante a disciplina “Comunicação Oral em Língua Inglesa: Desenvolvendo Habilidades”. Além de estudar aspectos linguísticos voltados para a habilidade oral, decidimos expandir o conteúdo disciplinar por meio da discussão das questões acima levantadas. Para tanto, utilizamos como um dos textos de partida um diálogo intitulado “Quem quer falar inglês na China?", veiculado na internet e de autoria desconhecida (Anexo 2). Os alunos-professores, então, discutiram as seguintes questões, com base em proposta de Monte Mór (2010): "Existe conflito nesses contextos de uso de inglês? Se sim, que palavras causaram esse conflito?”; “Quem tem razão? Por quê?”; “Algum falante deve se adaptar ao outro? Se sim, quem?”; “Algum falante fala 'errado'? Se sim, quem?”; "Você considera que houve comunicação no diálogo? Por que (não)?”; "Você já passou por alguma situação semelhante?”; "Você trabalharia esse diálogo com seus alunos? Se sim, o que você ensinaria?"; "Como você relaciona os conceitos de comunicação até agora discutidos com este diálogo?”

Questões como variação hegemônica, falante ideal e tratamento do erro foram levantadas pelos professores. Foram trabalhados alguns conceitos discutidos em Graddol (1997, 2006) como a legitimação crescente do inglês como língua estrangeira e a revisão do papel do falante nativo, com o 
objetivo de convidar os professores a questionarem a concepção eurocêntrica de "língua ideal" e de pronúncia precisa e correta via apagamento de sotaques e de identidades.

Entusiasmada com a atividade, Pâmela $^{1}$, uma das professoras participantes do curso, decidiu transpor nossas discussões para a sua prática pedagógica, o que lhe serviu como coleta de dados para o trabalho de conclusão do curso. A professora trabalhou o mesmo diálogo com seus alunos do Ensino Médio na escola estadual onde atua, localizada em bairro periférico da zona sul da cidade de São Paulo. O trecho abaixo, gentilmente cedido por Pâmela, constitui parte da transcrição de sua aula:

Pâmela = Agora que já leram o diálogo, O que significa a palavra "tanjooberrymutts"?

$\mathrm{As}^{2}$ : thank you very much.

((Alguns alunos nesse momento disseram: "É mesmo, como eu não vi antes?")) $)^{3}$

Pâmela: Qual a língua utilizada no texto?

((Aqui alguns alunos ainda tinham dúvidas))

As (em coro): Inglês... eu acho que é inglês.

Pâmela: Houve comunicação?

As: Teve sim, professora

A: É apesar do cliente ficar repetindo o tempo todo... teve.

Pâmela: Quem foi errado nesse diálogo? Por quê?

$\mathrm{A}: \mathrm{Ah}$ ! Eu acho que o atendente, porque é o trabalho dele, então ele tem que falar e atender bem pra continuar trabalhando.

A: Eu não acho, o cliente foi para outro país então ele tem que saber que lá não fala a língua dele.

A: É, então se for assim ninguém ta errado, mas porque esse inglês do atendente ta tão diferente?

((Neste momento expliquei que não deveríamos levar em consideração a parte escrita, pois a atividade se baseava na leitura das falas))

Pâmela: Se você fosse o cliente, você teria uma atitude diferente?

A: Ah eu ia reclamar com o gerente (risos)... to brincando acho que não. Não.

A: Eu ia fazer igual, só que depois eu acho que ia tentar ensinar ele a falar direito.

Pâmela: Então o inglês falado pelo atendente está errado?

As: Claro né? olha só como ele fala!

As: Professora existe só dois inglês, o Britânico e o Americano e ele não fala nenhum desses dois, então ele ta errado.

Pâmela: Será mesmo que só existem "dois inglês?” Bom então vamos lá, que língua nós falamos?

As: Português.

Pâmela = E na Bahia, Rio de Janeiro, Minas Gerais etc?

A: Ué professora também português.

Pâmela: Mas nós falamos igual a eles?

A: Não. Eles têm um sotaque diferente do nosso.

Pâmela: Mas também é português não é? Então porque a língua falada pelo atendente chinês no diálogo não pode ser o inglês?

A: Ah! Então é só o sotaque dele.

Pâmela: Gente, vamos então pensar agora na questão do inglês Britânico e Americano levantada pelo

Cleber. Será que o inglês falado em todo o mundo ou é britânico ou é americano? Não, na África do

Sul, em Camarões, na Índia, na Jamaica eles também falam inglês, mas eles tem o seu próprio sotaque e nem por isso deve ser considerado um "inglês" errado. Então porque será que temos que aprender ou o britânico ou o americano?

As: Porque foi na Inglaterra que surgiu o inglês e o inglês americano é o mais popular.

\footnotetext{
${ }^{1}$ Pseudônimo.

${ }^{2} \mathrm{~A}=$ Aluno(a); As = Alunos(as)

${ }^{3}(())=$ explicações adicionais de Pâmela ao longo da transcrição
} 
Pâmela: Realmente existe a questão do poder, mas nem por isso os países menos privilegiados devem ser considerados falantes de um inglês pobre ou errado. Tudo bem? Então vamos assistir um vídeo para ver se vocês conseguem identificar que língua está sendo falada nele.

((Neste momento coloquei o vídeo The English Language in 24 accents. À medida em que os alunos assistiam, cada vez mais se surpreendiam e em alguns momentos chegavam a rir))

Pâmela: Alguém sabe me dizer qual foi a língua usada neste vídeo?

A: Tem hora que parece inglês, mas tem hora que não.

Pâmela: O idioma utilizado durante todo o vídeo foi o inglês, porém inglês falado em várias partes do mundo e não só o Britânico ou o Americano. Como nossa aula já chegou ao fím vou deixar o nome do vídeo aqui na lousa e quem tiver interesse pode acessá-lo em casa, só lembrando que existem vários outros vídeos sobre o mesmo assunto...

Como podemos notar, as questões levantadas pelos autores supracitados emergiram na prática pedagógica de Pâmela, que instigou seus alunos a questionarem seus próprios entendimentos de língua (inglesa), de comunicação, de falante ideal, de identidade cultural, e ainda soube contextualizar o assunto articulando o conteúdo do diálogo aos diferentes usos da língua portuguesa em contextos brasileiros quando ela diz “E na Bahia, Rio de Janeiro, Minas Gerais, etc?”, convidando seus alunos a articularem aquilo que estavam aprendendo ali com os conhecimentos trazidos para a escola, em consonância, portanto, com a proposta de expansão de perspectivas individual, comunitária e global de Monte Mór (ibidem), por meio do trabalho de letramento crítico.

\section{CONSIDERAÇÕES FINAIS}

Segundo Vazquez (2007), uma filosofia da práxis apresenta o conceito de práxis como uma interlocução entre teoria e prática. No entendimento do autor, não há práxis como atividade puramente material, isto é, sem a produção de fins e conhecimentos que caracteriza a atividade teórica. Em nossa leitura, a práxis de que trata o autor constitui um dos desafios trazidos por novos movimentos educacionais, dentre as quais, as novas teorias de letramento que fundamentam as propostas discutidas neste artigo.

Atualmente, cerca de vinte universidades públicas do país estão em pleno processo de transposição dessas teorias globais para seus contextos locais, orientados por um Projeto Nacional de Formação de Professores de Inglês intitulado "Novos letramentos, multiletramentos e o ensino de línguas estrangeiras" ${ }^{\prime 4}$. O projeto tem como principal objetivo planejar, implementar e acompanhar programas locais para o ensino crítico de língua inglesa. Assim, as atividades que compartilhamos neste artigo se inserem no escopo do Projeto, constituindo duas ações nas quais pesquisadores e professores de inglês de escolas públicas e privadas tiveram a oportunidade de implementar novas práticas de ensino de inglês.

\footnotetext{
${ }^{4}$ http://dgp.cnpq.br/buscaoperacional/detalhegrupo.jsp?grupo=00678027EO09GQ\#identificacao
} 
O trabalho de letramento visual (a interpretação de imagens fotográficas) sugerido na primeira atividade se insere no movimento dos novos letramentos, questionando uma leitura exclusivamente linear e textual, trazendo a possibilidade de leitura visual contextual, por meio da qual discussões sobre reprodução e produção de interpretações são focalizadas. Já a segunda atividade prioriza o trabalho de letramento crítico tomando como ponto de partida a habilidade oral, com vistas à desconstrução dos conceitos de comunicação e falante ideal. Acreditamos que tais abordagens expandem não apenas o desenho curricular dos cursos de formação docente, mas também as realidades pedagógicas dos professores participantes, um reflexo da própria expansão de perspectivas provocada pelos e nos sujeitos envolvidos, incluindo-se, aqui, nossas próprias práxis, em constantes expansões.

\section{REFERÊNCIAS}

CASTELLS, M. Network Society. Oxford: Blackwell ( $2^{\text {nd }}$ ed.), 2000.

COMBER, B. Critical literacies and local action: teacher knowledge and a 'new' research agenda. In: COMBER, B.; SIMPSON, A. (eds.) Negotiating critical literacies in classrooms. New Jersey: Lawrence Erlbaum Associates Publishers, 2001.

COPE, B.; KALANTZIS, M. (eds.) Multiliteracies: literacy learning and the design of social futures. London: Routledge, 2000.

EDWARDS, R.; USHER, R. Globalization and pedagogy: space, place and identity. United States: Routledge. 2008, $2^{\text {nd }}$ edition

FERRAZ, D.M. EELT Education through English Language Teaching and Visual Literacy: an interweaving perspective. In: Contexturas, v. 17, p. 39-56, $2010 \mathrm{~b}$.

GEE, J. P. Situated language and learning - a critique of traditional schooling. United Kingdom: Routledge, 2004.

GUILHERME, M. English as a global language and education for cosmopolitan citizenship. Language and Intercultural Communication, Vol. 7, No. 1, 2007, 72-90

GRADDOL, D. The future of English: a guide to forecasting the popularity of the English language in the 21 century. London: British Council, 1997.

. English next: why global English may mean the end of 'English as a Foreign Language'. London: British Council, 2006.

IVES, P. Cosmopolitanism and Global English: Language Politics in Globalisation Debates. Political Studies Association, 2009.

KLEIMAN, A. Oficina de leitura. Campinas: Pontes, 1992. 
KNOBEL, M.; LANKSHEAR, C. (eds.). A New Literacies sampler. NY: Peter Lang Publishing, 2007.

KRESS, G. Design and transformation: new theories of meaning. In: COPE, B.; KALANTZIS, M. (eds.) Multiliteracies: literacy learning and the design of social futures. London: Routledge, 2000.

. Literacy in the new media age. New York: Routlegde, 2003.

LANKSHEAR, C. \& KNOBEL, M. New Literacies: Changing Knowledge and Classroom Research. Buckingham: Open University Press, 2003.

LANKSHEAR, C. \& SNYDER, I. with Green, B. Teachers and Technoliteracy: Managing literacy, learning and new technology in schools. Sydney: Allen \& Unwin, 2010.

LEVY, P. Cyberculture. Mineapolis \& London: University of Minnesota Press, 2001.

MENEZES DE SOUZA, L. M. T. Para uma redefinição de Letramento Crítico: conflito e produção de Significação. In: MACIEL, R. F. E ARAUJO, V. A. (Orgs.) Formação de professores de línguas: ampliando perspectivas. Jundiaí: Paco Editorial, 2011.

MONTE MÓR, W. Linguagem e Leitura da Realidade: Outros olhos, Outras Vozes. Tese de Doutorado. Não publicada. São Paulo: USP, 1999.

. Foreign languages teaching, education and the new literacies studies: expanding views. In: GONÇALVES, G. R. et al (Orgs.). New Challenges in Language and Literature. Belo Horizonte: FALE/UFMG, 2009.

- Caderno de Orientações Didáticas para EJA - Inglês. São Paulo: Secretaria Municipal de Educação, 2010. Disponível em http://portalsme.prefeitura.sp.gov.br/Projetos/BibliPed/Documentos/publicacoes/orienta_ing_portal.p df Acesso 15 Abril 2011.

. Critical literacies in the Brazilian university and in elementary/secondary schools: the dialectics between the global and the local. In: MACIEL, R. F. E ARAUJO, V. A. (Orgs.) Formação de professores de línguas: ampliando perspectivas. Jundiaí: Paco Editorial, 2011.

MILLS, K. A. "A Review of the 'Digital Turn' in the New Literacies Studies". In Review of Educational Research. Vol. 80. N. 2, pp 246 -271. New York; SAGE, 2010. Disponível em $<$ http://rer.sagepub.com/content/80/2/246>

MUSPRATT, S., LUKE, A.; FREEBODY, P. (Eds.). Constructing Critical Literacies. Cresskill, New Jersey: Hampton Press, 1997

PENNYCOOK, A. The cultural politics of English as an International language. United Kingdom: Longman Group Limited, 1994.

Critical Applied Linguistics: a critical introduction. New Jersey: Lawrence Erlbaum Associates, Inc., 2001. 
RIZVI, F.; LINGARD, B. Globalizing education policy. New York: Routledge, 2010.

SHOR, I. "What is Critical Literacy?". In: DARDER, BALTODANO \& TORRES (eds). The Critical Pedagogy Reader. London; Routledge, 2009.

SOARES, M. Alfabetização e letramento têm o mesmo significado? Rev. Pátio, ano IX, n.34, p.5052, mai/jul 2005.

STREET, B. Social literacies: critical approaches to literacy in development, ethnography and education. London and New York: Longman, 1995.

New Literacies in theory and practice: what are the implications for language in education? Linguistics and Education, vol.10 (1), 1998, 1-24

What's "new" in New Literacy Studies? Critical approaches to literacy in theory and practice. Current Issues in Comparative Education, Teachers College, Columbia University, Vol. 5(2), 2003.

VAZQUEZ, A. S. Filosofia da praxis. São Paulo: Expressão Popular, 2007.

WARK, M. Cyberculture studies, and antidisciplinary approach. New York and London: New York University Press, 2006.

WARSCHAUER, M. The Changing Global Economy and the Future of English Teaching. Tesol Quarterly Vol. 34, No. 3, 2000, 511-535

YANO, Y. English as an international lingua franca: from societal to individual. World Englishes, Blackwell Publishing Ltd., Vol. 28, No. 2, 2009, 246-255 
DOSSIÊ ESPECIAL

JORDÃO (org.) Letramentos e Multiletramentos no Ensino de Línguas e Literaturas.

Revista X, vol.1, 2011

\section{ANEXO 1}

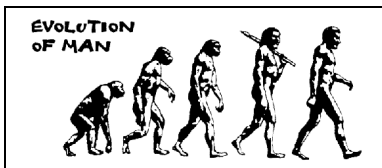

\section{AND WOMAN}

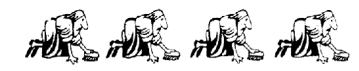
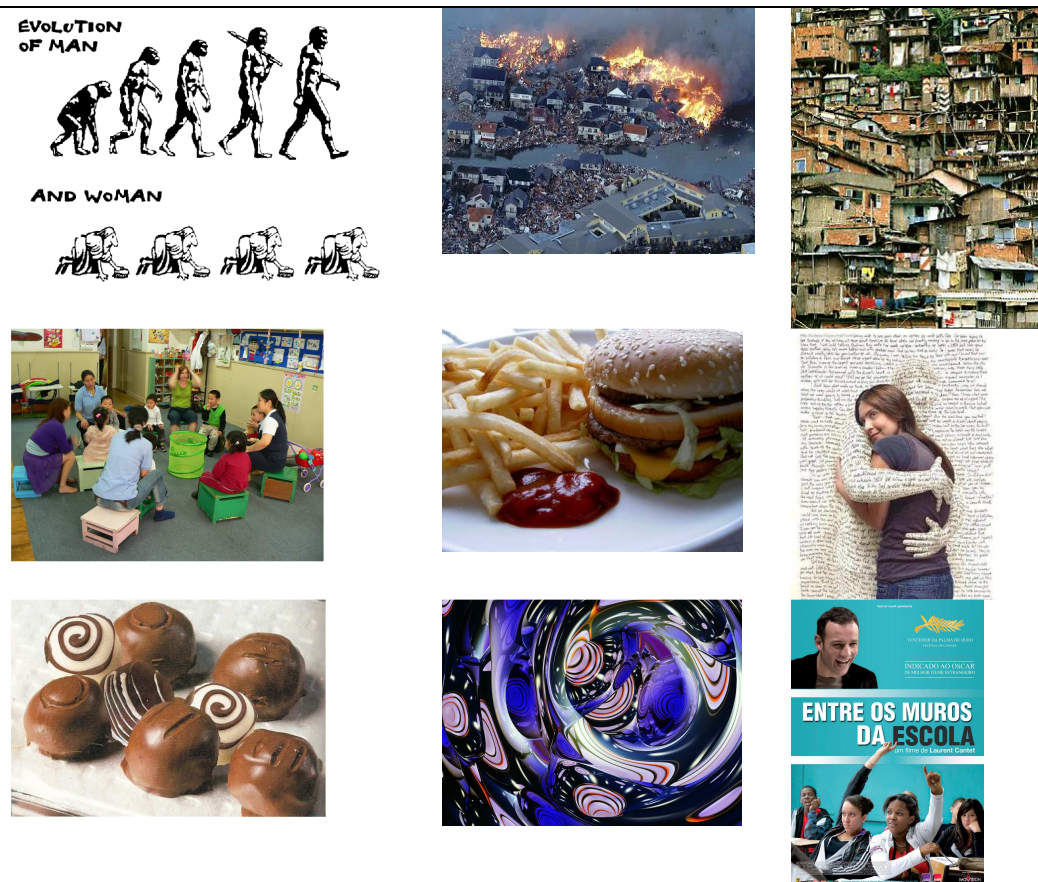

Figura 1: Imagens fotográficas para trabalho interpretativo ${ }^{5}$

\footnotetext{
5 Imagens disponíveis em <http://www.google.com/imghp $>$ Acesso em 10/04/2011
} 
DOSSIÊ ESPECIAL

JORDÃO (org.) Letramentos e Multiletramentos no Ensino de Línguas e Literaturas.

Revista X, vol.1, 2011

\section{ANEXO 2 \\ QUEM QUER FALAR INGLÊS NA CHINA?}

Fonte: Texto veiculado na Internet

What does TANJOOBERRYMUTTS mean in English language?

By the time you read through this you will understand what " TANJOOBERRYMUTTS " is and be ready for

China. In order to continue getting-by in China, we need to learn English the way it is spoken. Practice by reading the following conversation until you are able to understand the term " TANJOOBERRYMUTTS ".

With a little patience, you'll be able to fit right in.

The following is a telephone exchange between maybe you as a hotel guest and room-service today:

Room Service : "Morrin. Roon sirbees."

Guest : "Sorry, I thought I dialed room-service."

Room Service: " Rye . Roon sirbees...morrin ! Joowish to oddor sunteen ???"

Guest: "Uh..... Yes, I'd like to order bacon and eggs."

Room Service: "Ow ulai den ?"

Guest: ".....What ??"

Room Service: "Ow ulai den ?!?... Pryed, boyud, pochd ?"

Guest: "Oh, the eggs ! How do I like them ? Sorry.. Scrambled, please."

Room Service: "Ow ulai dee bayken ? Creepse ?"

Guest: "Crisp will be fine."

Room Service: "Hokay.. An sahn toes ?"

Guest: "What?"

Room Service: "An toes.. ulai sahn toes ?"

Guest: "I.... Don't think so.."

Room Service: "No? Udo wan sahn toes ???"

Guest: "I feel really bad about this, but I don't know what 'udo wan sahn toes' means."

Room Service: "Toes! Toes !...Why Uoo don wan toes ? Ow bow Anglish moppin we botter ?"

Guest: "Oh, English muffin !!! I've got it ! You were saying 'toast'... Fine...Yes, an English muffin will be fine."

Room Service: "We botter?"

Guest: "No, just put the botter on the side."

Room Service: "Wad ?!?"

Guest: "I mean butter... Just put the butter on the side."

Room Service: "Copy ?"

Guest: "Excuse me ?"

Room Service: "Copy...tea.. meel ?"

Guest: "Yes. Coffee, please... And that's everything."

Room Service: "One Minnie. Scramah egg, creepse bayken , Anglish moppin, we botter on sigh and copy ... Rye ??"

Guest: "Whatever you say."

RoomService: "Tanjooberrymutts."

Guest: "You're welcome" 